\title{
Estimation of the Deposited Aerosol Particles in Baghdad City, using Image Processing Technique
}

\author{
Huda Al-Ameer Abood \\ College of Science, \\ Al-Mustansiriya University \\ Baghdad-Iraq
}

\author{
Ali A. Al-Zuky \\ College of Science, \\ Al-Mustansiriya University \\ Baghdad-Iraq
}

\author{
Anwar H. M. Al-Saleh \\ College of Science, \\ Al-Mustansiriya University \\ Baghdad-Iraq
}

\begin{abstract}
In this study, an algorithm was developed to measure the volume and the covered area by the dust particles, and the radius of dust particle deposited for different time hours of the day. Slices transparent glass has been used to collect samples of dust particle deposited for different time of the day in Rusafa area of Baghdad city, were taken digital image of the samples through an optical microscope (EYEPIECE 10X). What have been noticeable are the difference in radii and areas of dust particles deposited as well as the difference in the density of dust particles for each slice according to time that put the slice to deposition.
\end{abstract}

\section{Keywords}

Dust particle, Atmospheric Aerosols.

\section{INTRODUCTION}

Air pollution is one of the important problems in latest decades, with increasing use of fuels from oil and natural gas in various fields of life, spread in the environment many air pollutants such as gases resulting from industrial activities or different modes of transport [1].Air pollutants are classified according to the nature of its presence into two main groups: gaseous pollutants and aerosols. An example of gaseous pollutants and hydrocarbons that exist in the form of organic compounds may be gaseous, liquid or solid, such as sulfur oxides, nitrogen oxides and carbon [2]. The aerosol pollutants other are divided into solid and liquid non-permanent, such as the normal dust and pollen. Aerosol sooner or later precipitates out of the air but gases, containing space which launches it and act like the air and will not precipitate [3]. Aerosol light-absorption measurements are important for health, climate, and visibility applications [4].

Michael D. King et al. (1999) [5] Studied the advantages and disadvantages systems of Remote sensing for aerosol application, Where no one sensor system is capable of providing totally unambiguous information. Also a careful intercomparison of derived products from different sensors, to gather with comprehensive network of ground-based sun photometer and sky radiometer systems. W.Partrick Arnottet. al.(2005)[4] exploited the aerosol optics use in experiment develop a model-based calibration scheme for the 7wavelength aethalometer, and the photo acoustic instrument operating at $532 \mathrm{~nm}$ is used to evaluate the filter loading effect caused by aerosol light absorption and multiple scattering theory is used to analytically obtain a filter-loading correction function. G. J. Wong et al. (2007) [6] Studied the temporal development for air quality, was develop the image processing technique for enhancing the capability of an internet video surveillance (IVS) camera for real time air quality monitoring, in this technique could to detect particulate mater with diameter less than 10 micrometers(PM10).Xiaolei Yu et. al. (2011) [7] introduced a relationship between aerosol anthropogenic component and air quality in the city of Wuhan, by used satellite remote sensing. A. Bagatet. al. (2013) [8] exploit the aerosol optical depth, Angstrom exponent, single scattering albedo, and polarized phase function have been retrieved from polarized sun-photometer measurements for atmosphere. Where the Angstrom exponent has a meaningful variations respect to the changes in the complex refractive index of the aerosol, and the polarized phase function shows a moderate negative correlation respect to aerosol optical depth and single scattering albedo, so polarized phase function became regarded as a key parameter to characterize the aerosol. In this paper, measuring system will be introduced for determine radius, covered area by deposited aerosol particle and deposited aerosol particle volume as a function of day time, will be calculated by using image analysis and computer algorithms.

\section{ATMOSPHERIC AEROSOLS}

Aerosols are minute particles suspended in the atmosphere. When these particles are sufficiently large can be observed their presence as they scatter and absorb sunlight. Was the scattering of sunlight can reduce visibility (haze) and redden sunrises and sunsets [9]. Measured the size in unit micrometer, particle largest of 50 micrometers can be seen by the naked eye but smaller of (0.005) micrometers can be observing it only in electronic microscope. where that extreme importance of particles in the study of air pollution which their ranging size from $(0.01-100)$ micrometers and particles younger than 10 micrometers tend not to quickly sedimentation, so remain in the atmosphere for a long time either the fumes, smoke, metal dust, cement, fly ash, carbon black and spray sulfuric acid all located within the range (10 100) micrometers which are larger and heavier than the outstanding and deposited of near their sources. The deposition process of these particles is the most important natural process to self-cleaning of remove the particle from the air [10]. Particles are typically classified as total suspended particulate (TSP: comprising all particle sizes), medium to fine particulate (PM10: particles less than $10 \mathrm{~mm}$ in diameter), fine particulate (PM2.5: particles less than 2.5 $\mathrm{mm}$ in diameter), and ultra-fine particulate (PM1.0 and smaller). Fine particles, or PM2.5, are the most significant contaminant influencing visibility conditions because their specific size allows them to scatter or absorb visible light. It also allows them to remain airborne for long periods of time, and under favorable climatic conditions they may be transported over long distances. This is one reason why locations distant from the main pollution sources.Secondary reactions are influenced by a wide range of factors, such as temperature, sunlight, the mixture of gases present, and time. Secondary formation of particles from gaseous pollutants can take some time to occur and will be exacerbated under conditions of low wind speed and poor dispersion [11]. The major component comes in the form of sulfate aerosols created by the burning of coal and oil. The concentration of 
human-made sulfate aerosols in the atmosphere has grown rapidly since the start of the industrial revolution. At current production levels, human-made sulfate aerosols are thought to outweigh the naturally produced sulfate aerosols. The sulfate aerosols absorb no sunlight but they reflect it, thereby reducing the amount of sunlight reaching the Earth's surface. Sulfate aerosols are believed to survive in the atmosphere for about 3-5 days [9].

\section{TOTAL OPTICAL DEPTH (TOD)}

Expresses the amount of scattering and absorption of radiation occurring in the atmosphere and when was this value higher the atmosphere will be worst and seeing orbs hardest. TOD Mainly consists of two components First: aerosol optical depth (AOD) second: Rayleigh optical depth(ROD) Add other components are not have the effect dispersion and absorption is happening among layer and the other because of other rare gases scientific researches suggests that most of the pollution is at an altitude of less than (1500_2000) meters. (ROD) is the dispersion and absorption which are happening because of the same components of the atmosphere (nitrogen/ oxygen) value generally small and it not change in one place they fixed rate so it was interesting all global campaigns the value (AOD) is the value that cannot be calculated accurately or even expected in the future and as was change dramatically (AOD) dispersion and absorption which are happening in the atmosphere due to hanging from dust, fumes and ashes and other large plankton [12].

\section{IMPORTANCE OF AEROSOL MEASUREMENTS}

Interesting in the aerosol measurements, Due to being everywhere, it's changing and complex structure, and interacts with their surroundings in the atmosphere, Where concentrations varies from less than (1- 106 particles) per $\mathrm{cm} 3$ [13], their shape may be perfectly spherical or almost cluster complex, can be changing in color from white to black [14]. The aerosol measurements and its relation with changes atmospheric condition could give an indication of the movement of the future of the earth's atmosphere, that's where particle aerosol change qualities atmosphere very slowly [15]. Also their impact on human health, that the aerosol particles interacts directly with humans where are inhalation of fine dust harmful, smoke machines diesel and asbestos fiber, thus these particles can stimulate the cells leads to a acute change and fast, for example, haemostatic [16]. Therefore measurements were needed to aerosol to long ranges lead to know the nature of the particles and then develop models more accuracy [15].

\section{DRAWING SCALE (SCALE FACTOR)}

All drawings can be classified as either drawings with scale or those drawn to scale. Drawings without a scale usually are intended to present only functional information about the component or system. Prints drawn to scale allow the figures to be rendered accurately and precisely. Scales drawn also allow components and systems that are too large to be drawn full size to be drawn in a more convenient and easy to read size [17]. The opposite is also true. A very small component can be scaled up. Or enlarged, so that its details [18]. Scale drawings usually present the information used to fabricate or construct a component or system. If a drawing is drawn to scale, it can be used to obtain information such as physical dimensions, tolerances, and materials that allows the fabrication or construction of the component or system, every dimension of a component or system does not have to be stated in writing on the drawing because the user can actually measure the distance (e.g., the length of a part) from the drawing and divide or multiply by the stated scale to obtain the correct measurements [18].

\section{STUDY AREA}

Baghdad city is located in central of Iraq within the sector of flat sedimentary plain (Latitude $33.2^{\circ} \mathrm{N}$, Longitude $44.2^{\circ} \mathrm{E}$ ). It is consider center of economical and administrative, instructive for states. Were studied the amount of dust deposited on the slide precisely in Rusafa at Palestine street, it is classified a commercial residential area [19], at day (16-3 2013) the weather was between cloudy and partial cloudy with gradually rising dust during the day and the wind was southeasterly mild to moderate $(10-20) \mathrm{km} / \mathrm{h}$, and the visibility (6-8) $\mathrm{km}$, according to what has been obtained from the Public Authority for meteorological Iraqi [20].

\section{THE COLLECTION OF DEPOSED AEROSOL}

In this research have been studying the aerosol deposited in the cited region of Baghdad city by used the glass slide a thickness $(1 \mathrm{~mm})$. Where have been put the slice exposed to the air on height $(3 \mathrm{~m})$ on the earth's, and $(32 \mathrm{~m})$ on level of sea surface. Four slides placing in the same time, then dragging one slide after each (4) hours and keep it in the customized portfolio then using optical microscope (EYEPIECE 10X) to capture several images for the deposed aerosol on the glass slide. 4 images have been obtained for different slides and different times. The captured images of sizes $(1280 \times 1024)$ see

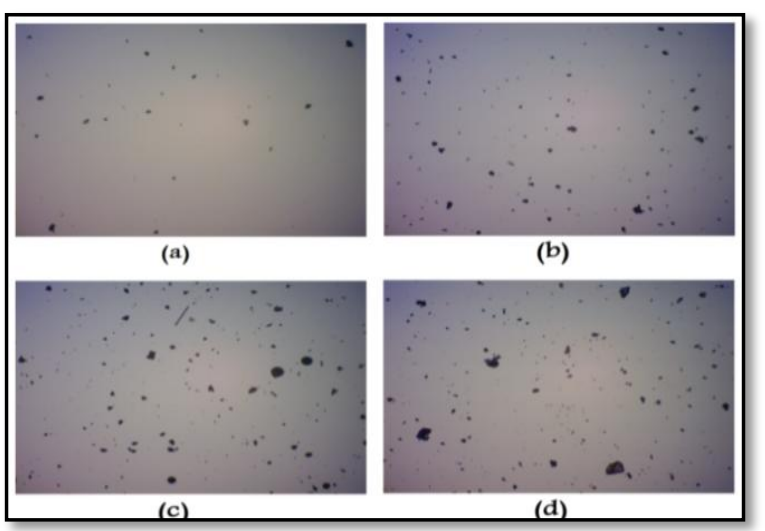

figure (1).

Fig 1: Image Microscope slide for (9am, 1pm, 5pm, 9pm) to image (a, b, c, and d) respectively.

\section{THE ADOPTED ALGORITHMS}

To analysis the aerosol deposited in Baghdad city using image processing technique the following algorithms were used:

1. Compute scf: To estimate the real aerosol dimensions, in the digital capture images, calibration sample of optical microscope was used. Calibration sample is a thin transparent slide chart contains lines very accurate, the width each line is $(\mathrm{Lr}=0.1 \mathrm{~mm})$. The image for the calibration sample by microscope was captured, (see Figure 2). Then calculate line width in the captured image for the bar lines in pixels, then compute the scaling factor to be used in estimate real length between any two point in the Image where used the proper click mouse to select two point $(x 1, y 1)$ and $(x 2, y 2)$ of a line at the edge to determining the length between two lines in the image plane manually by computer mouse, then compute the line's width in pixels (Lp) between first point $\mathrm{P}(1)(\mathrm{x} 1, \mathrm{y} 1)$ and second point $\mathrm{P}(2)(\mathrm{x} 2, \mathrm{y} 2)$ using the equation: 


$$
L_{p}=\sqrt{\left(x_{2}-x_{1}\right)^{2}+\left(y_{2}-y_{1}\right)^{2}}
$$

Then Compute scaling factor for this image using the equation:

$$
S c f=\frac{L_{r}}{L_{p}}
$$

Where the length between the two sides the line ( $\mathrm{Lr})$, and Lp represent the line's width in pixel.

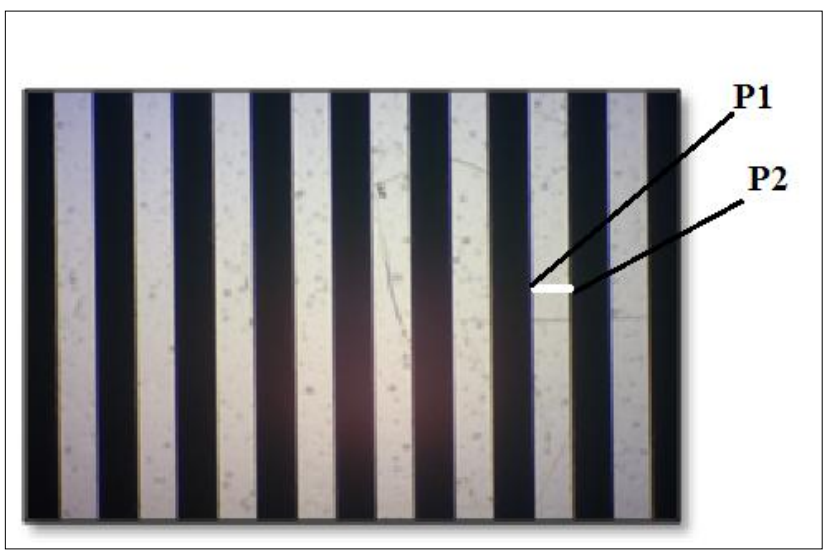

Fig 2: Show image Calibration sample (slide chart).

2. Aerosol image analysis algorithm: After capture the images for the four slices, was extracted n(i) blocks (i=1, 2, 3, 4), from each target such that most dust particles were taken (see figure 3), and the size of blocks are different depend on dust particle. Here the covered area will be compute, radius and volume of aerosol particle. In this study the radius of deposited aerosol particles was estimated by two methods:

Method (1): calculated the number of pixels of the deposited aerosol particle image (np).

Fig 3: The blocks of each dust particle in the 4-image

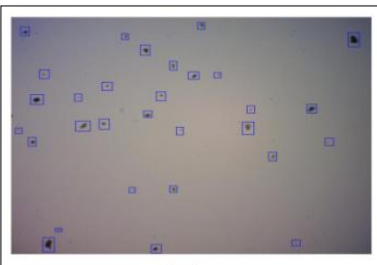

(a)

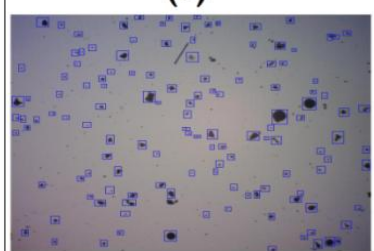

(c)

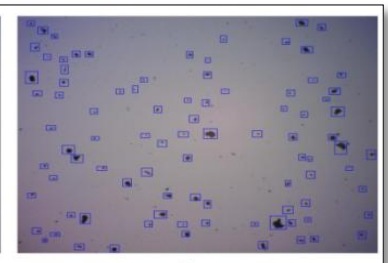

(b)

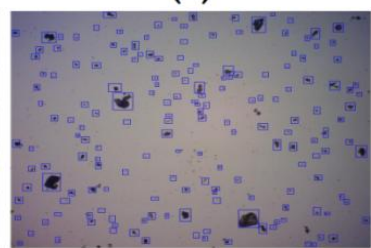

(d)
$\mathrm{R}_{1}=\sqrt{\frac{n p}{\pi}}$

The radius of aerosol particle in real world given by:

$\operatorname{Rr} 1=\mathrm{R} 1 * \mathrm{scf}$.

Where assume the aerosol particle have a spherical shape.

Method (2):

1- Determine the edge points of the aerosol particle, using Soble operator.

2-Estimate the center of the particle using:

$\mathrm{Xc} \frac{1}{N} \sum_{i=1}^{N} X i, \mathrm{Yc}=\frac{1}{N} \sum_{i=1}^{N} Y i$.

Where (Xi, Yi) represent appoint in the aerosol particle. The number of aerosol particle points $(\mathrm{N})$

3- Compute aerosol Radii for the particle (re) that represent the distance between the particle edge points $(\mathrm{Xe}, \mathrm{Ye})$ and the particle center $(\mathrm{Xc}, \mathrm{Yc})$ :

$\mathbf{r}_{\mathrm{e}}=\sqrt{(X e-X c)^{2}+(Y e-Y c)^{2}}$

The compute the average radius of (re):

$\mathrm{R}_{\mathrm{p} 2}=$ average $\left(\mathrm{r}_{\mathrm{e}}\right)$ in pixel unit

Then the radius of the aerosol particle in real world can be compute from.

$$
\begin{aligned}
& \mathrm{R}_{\mathrm{r} 2}=\mathrm{R} A=\pi R^{2} \ldots \\
& \mathrm{V}=4 / 3 \pi \mathrm{R}^{3} \ldots \ldots \ldots \\
& \mathrm{p} 2^{*} \operatorname{scf} \ldots \ldots \ldots(8)
\end{aligned}
$$

Then can be compute the covered area A, and the volume of the deposited aerosol particle using the radius of the particle that computed from method (1) Or method (2), after thatestimate the area (A) and the volume (V) of the aerosol particle as following: 


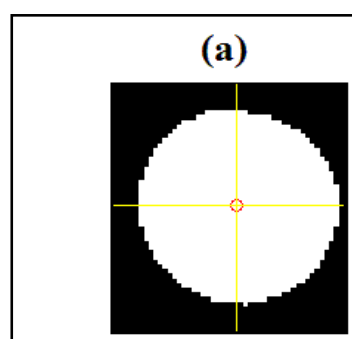

(c)

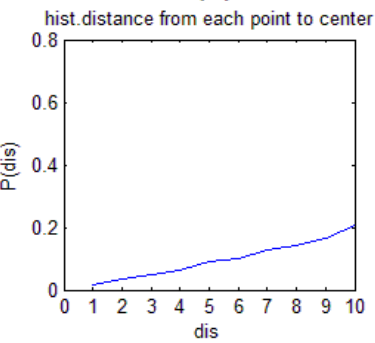

dis (b)

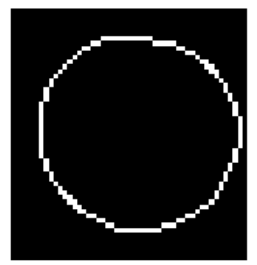

(d)

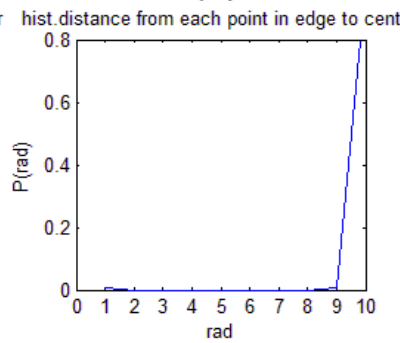

rad (a)

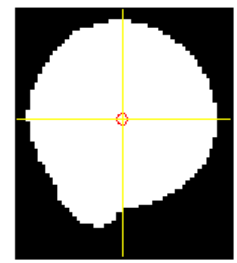

(c)

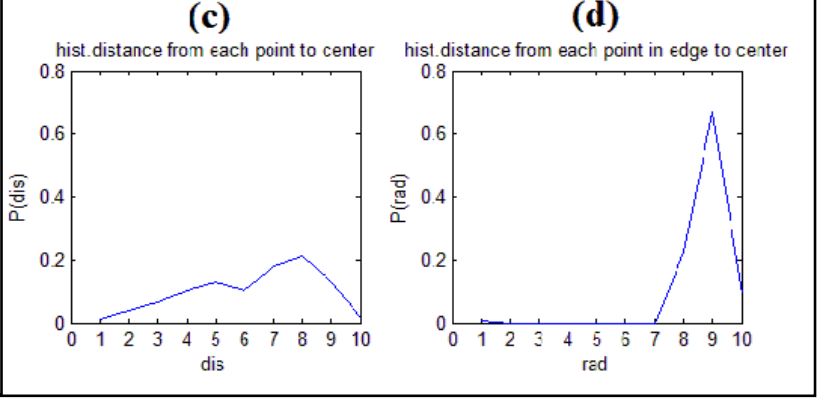

(b)

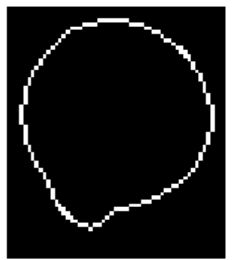

(d)

(a)dust particle (v=0.000103mm3)

(b) dust particle $(v=6.42 * 10-5 \mathrm{~mm} 3)$

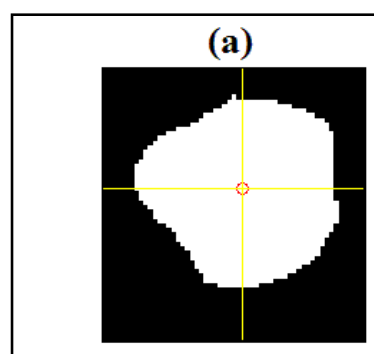

(c)

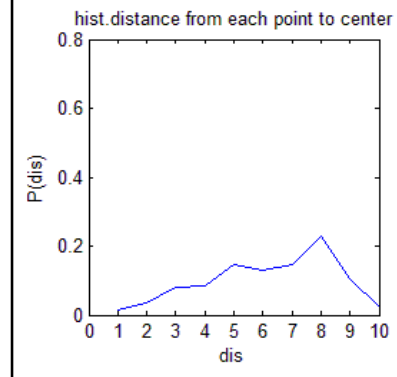

(c) dust particle $(v=4.21 * 10-6 \mathrm{~mm} 3)$ (a)

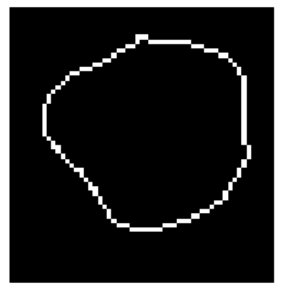

(d)

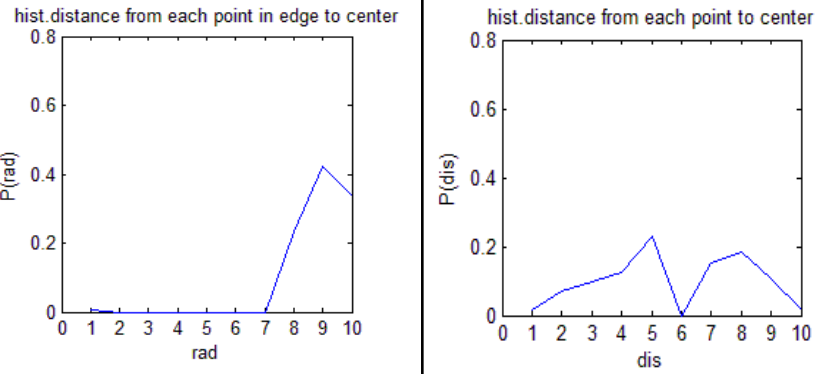




\section{RESULTS AND DISCUSSIONS}

After computing particle radius (R), area (A) and volume (V) of the deposited aerosol particles, the histogram for the aerosol particle radii, covered area and volumes shown in figure(5), can be noted that differences between the results when the different time periods of sedimentation.

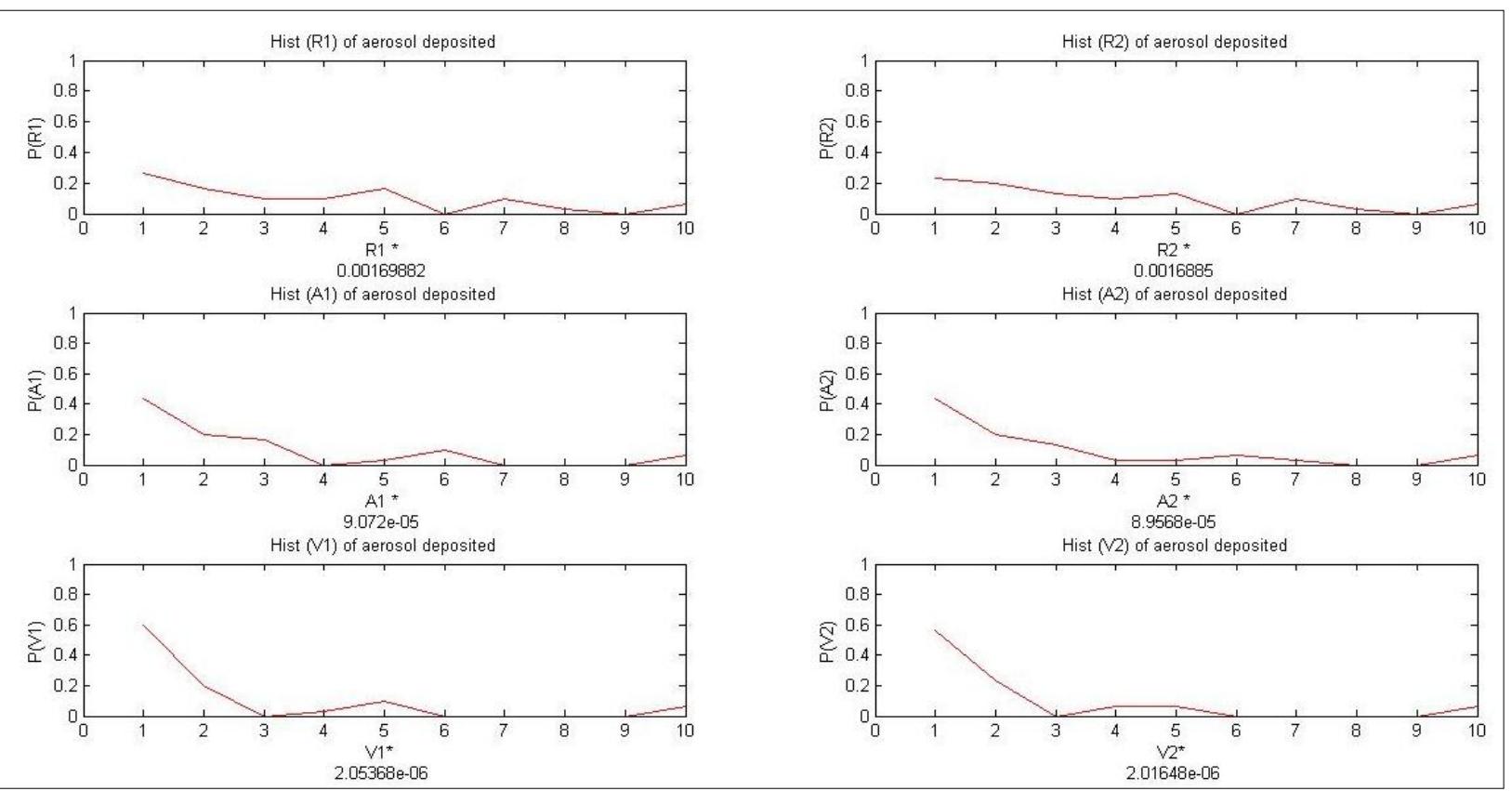

(a) Histogram for (R, A and V) of Image Microscope slide (9am).

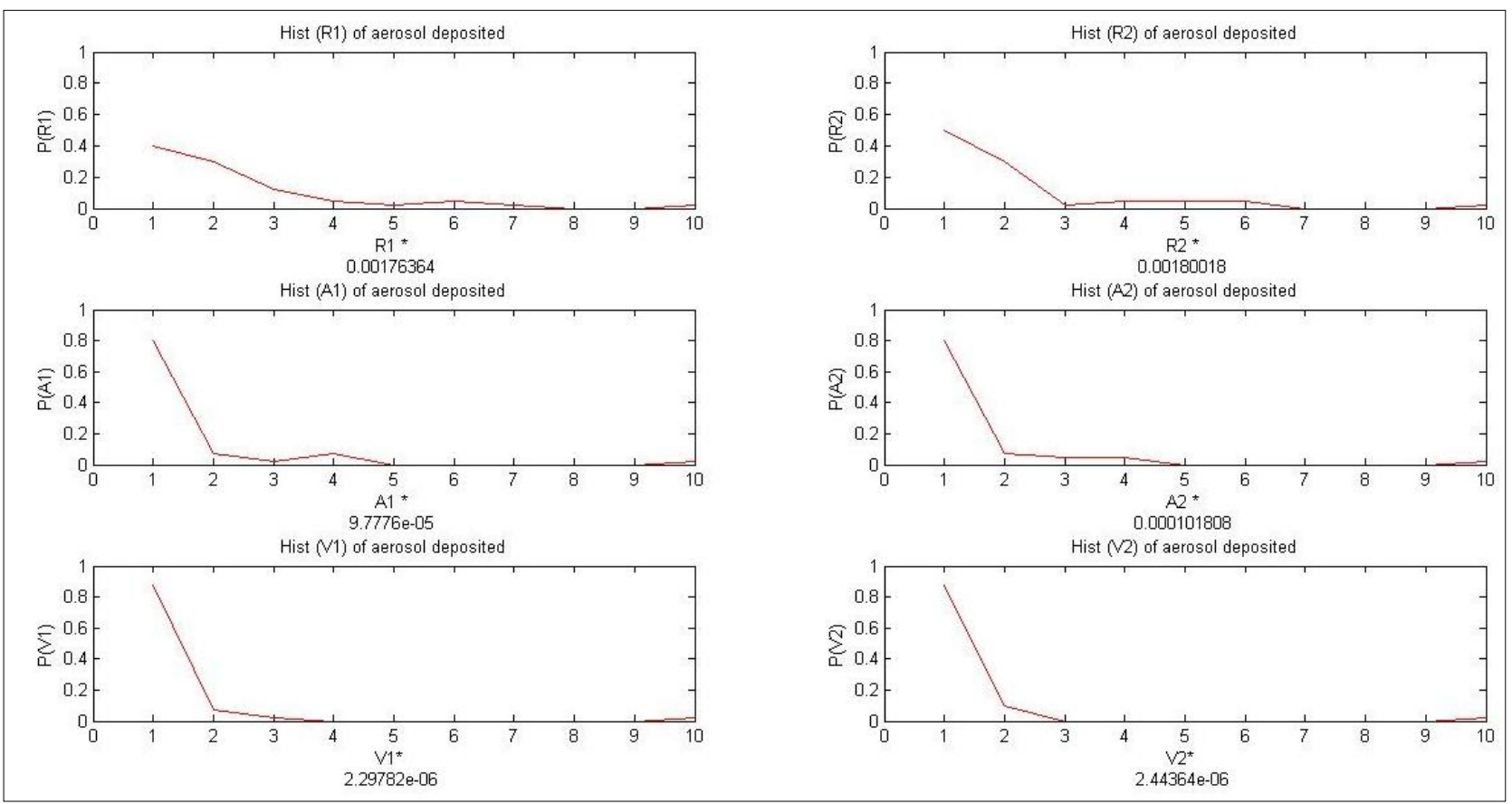

(b) Histogram for (R, A and V) of Image Microscope slide (1pm). 


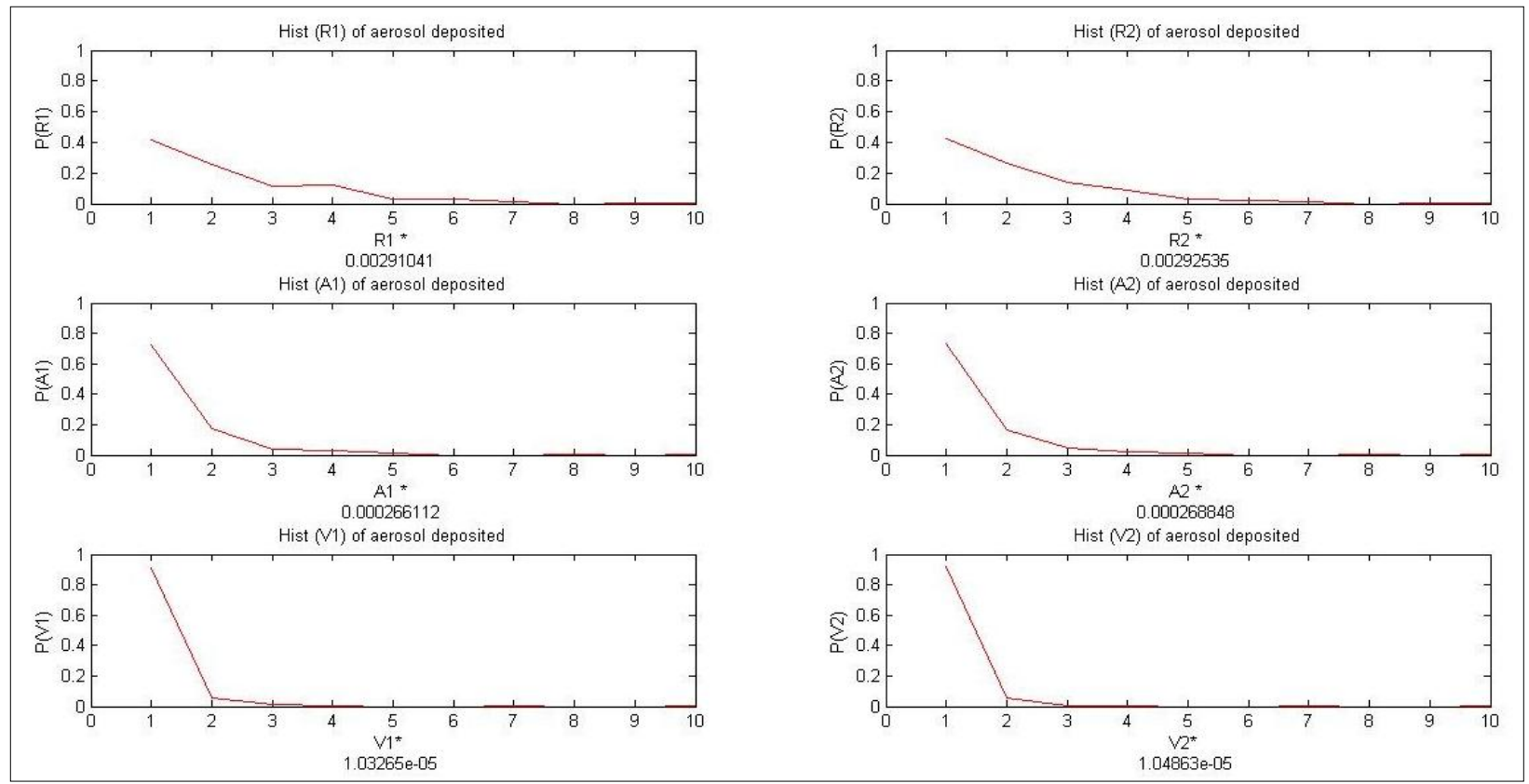

(c) Histogram for (R, A and V) of Image Microscope slide (5pm).

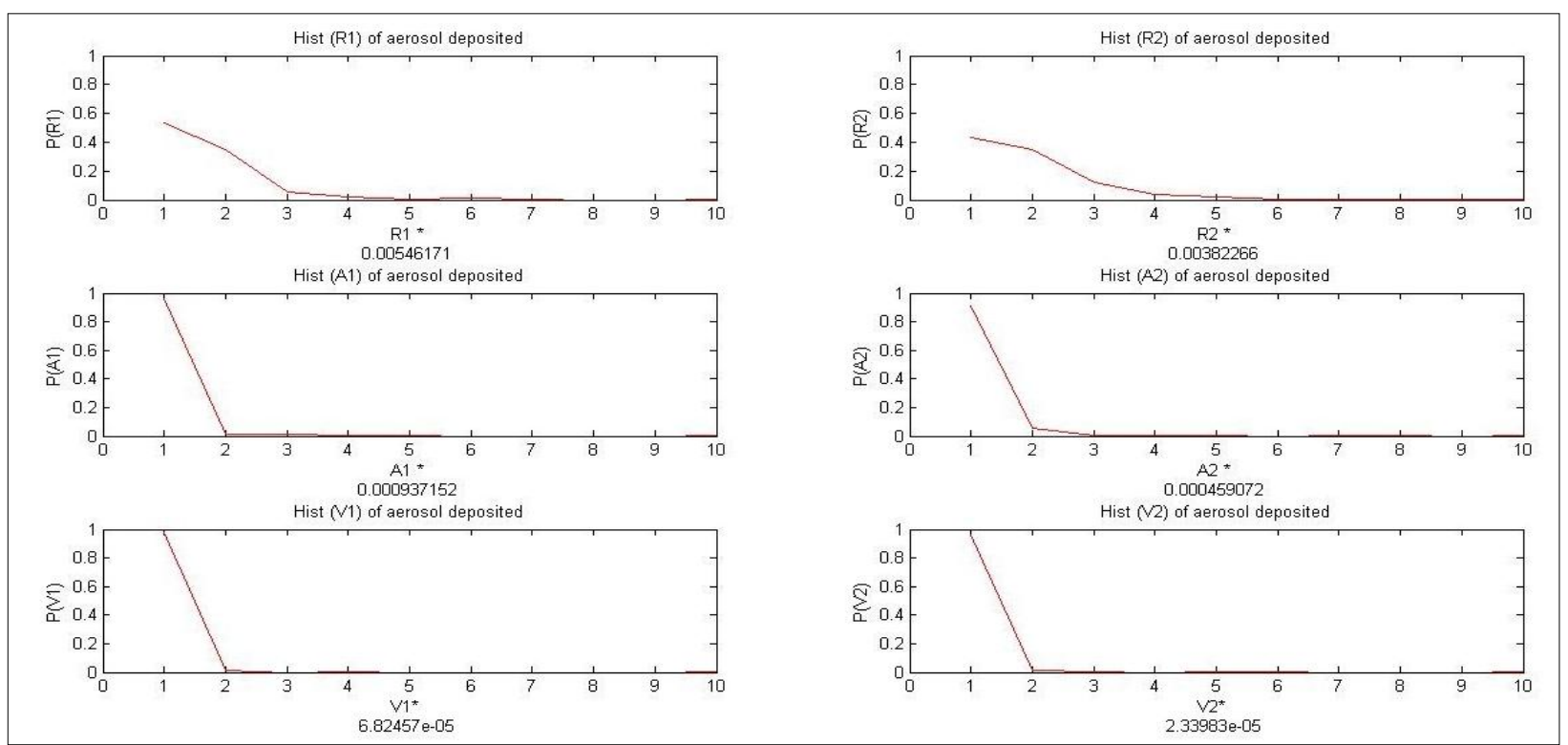

(d) Histogram for (R, A and V) of Image Microscope slide (9pm).

Fig 5: The histogram for the aerosol particle radii, covered area and volumes for images captured in (9am, 1pm, 5pm, 9pm). 
Can be noted that the histogram for the radius of (9am) was declining gradually at the probability of the deposited between small and large, and after that at $(1 \mathrm{pm})$ note that the beginning of the curve rise any increase in deposited particle of small sizes, but in the last hours, and with increased the sedimenting particles, the beginning of the curve will rises to a large extent, means the probability of increased deposition of small particles that need for a long time in order to deposited either large particles they deposited rapidly so its existence reduced because it is deposited in the first hours.

Where then found the minimum value of area (A) and volume (V) for two methods and the histograms for all cases, these shown in tables (1).

Table 1. Show minimum value of area and volume, shown in figure (7).

\begin{tabular}{|c|c|c|c|c|}
\hline $\begin{array}{c}\text { Time of } \\
\text { deposit }\end{array}$ & $\mathrm{A}_{1} \mathrm{~mm}^{2}$ & $\mathrm{~A}_{2} \mathrm{~mm}^{2}$ & $\mathrm{~V}_{1} \mathrm{~mm}^{3}$ & $\mathrm{~V}_{2} \mathrm{~mm}^{3}$ \\
\hline 4hour & 0.00004464 & 0.00003744 & $1.7333 \mathrm{E}-07$ & $2.24362 \mathrm{E}-07$ \\
\hline 8 hours & 0.00004176 & 0.00003168 & $1.34253 \mathrm{E}-07$ & $2.03004 \mathrm{E}-07$ \\
\hline 12 hours & 0.00003456 & 0.00002736 & $1.04825 \mathrm{E}-07$ & $1.52836 \mathrm{E}-07$ \\
\hline 16 hours & 0.00001728 & 0.00000864 & $2.05795 \mathrm{E}-08$ & $5.40355 \mathrm{E}-08$ \\
\hline
\end{tabular}
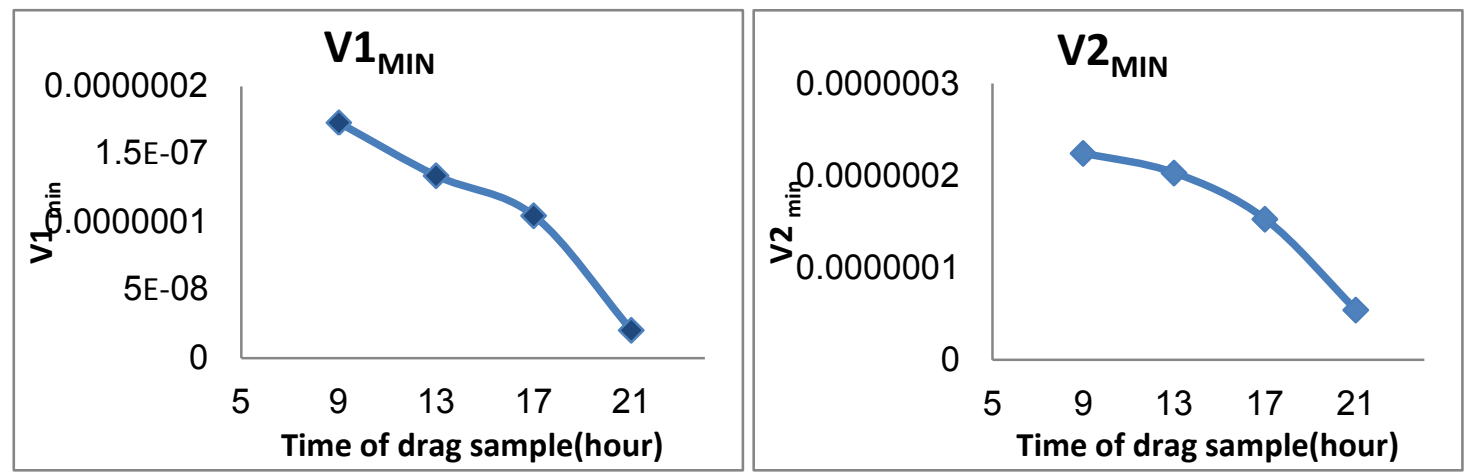

Fig 5: Show minimum value of volumes of aerosol particle of the two methods.

From the captured image have been extract all aerosol particles in blocks and applying the algorithm to calculate the radius, area and volume for all aerosol particles in the new image. Then calculate the rate the volume and area by dividing the summation of volume or area on size the image (TA), (see figure (7))

$$
\begin{aligned}
& \text { Arat }=\frac{\sum_{i}^{n} A i}{T A} . \\
& \text { Vrat }=\frac{\sum_{i}^{n} V i}{T A} .
\end{aligned}
$$



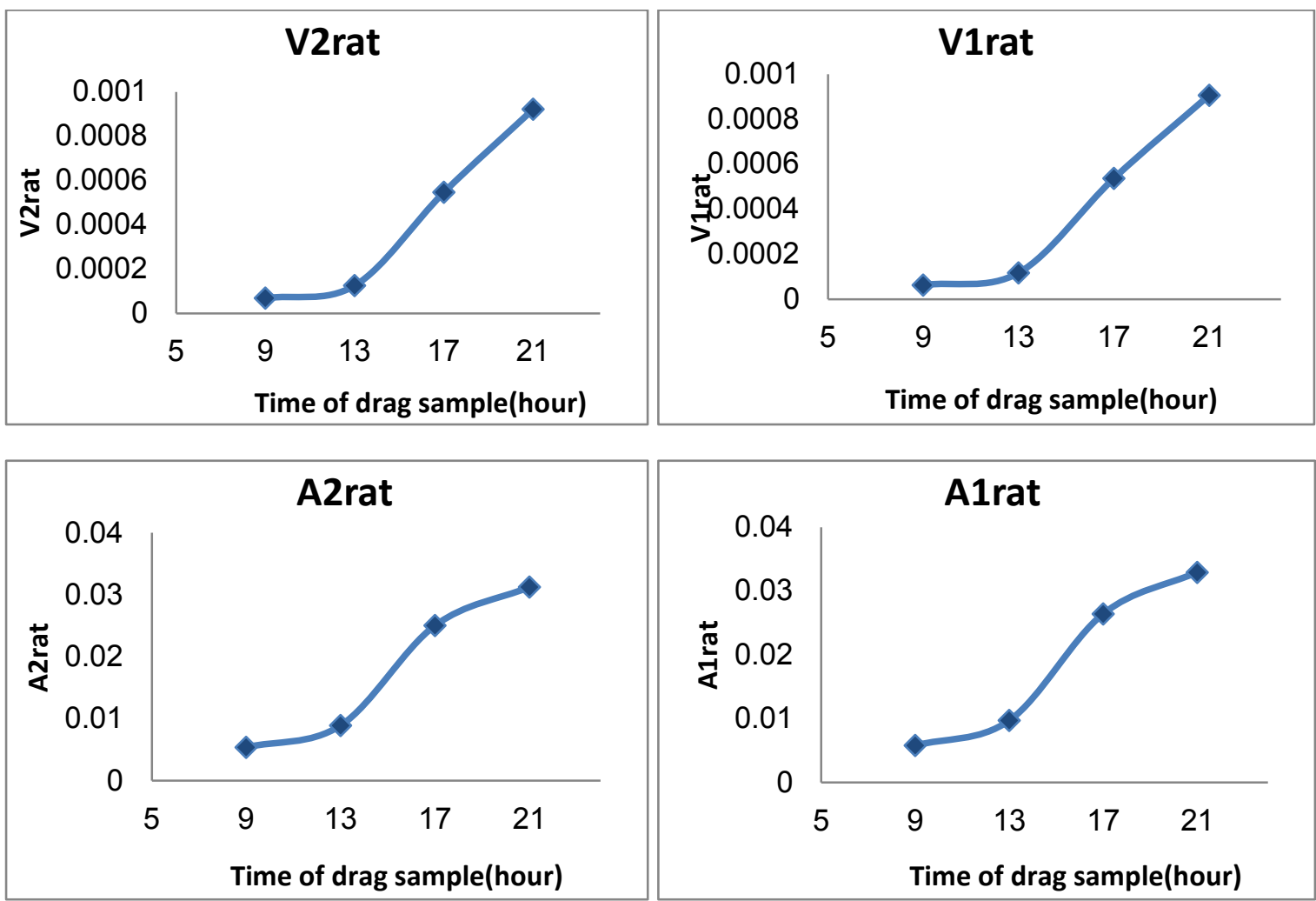

Fig 5: Show the rate for total $(\mathrm{A1}, \mathrm{A2}, \mathrm{V1}$ and $\mathrm{V2})$ in the image.

\section{CONCLUSION}

From the result can be concluded:

1-The density of dust particle deposited on the first slide (9am) very low aerosols comparing with the other, and the covered area to each dust particle is medium measurement.

2- There is significantly increased density of dust particle on the second slice and different kinds of shapes and sizes of dust particle, that can be observed from the histogram of the second slice the peaks is reduced for curve to areas (A1, A2) that means increased in Measurements the covered area of dust particle gradually from very small to large.

3-On the third slide $(5 \mathrm{pm})$ there was increased density but difference less the first cases (9am).

4-In the last $(9 \mathrm{pm})$ case was observed that the small particle of the dust is the most increased, this is due to small particle nature of slow deposition, and that clear in histogram, the Curved rise because the dust proportion increased due to increased hours of the deposition, and the start of the curve is rise at the low values of covered area to dust particle, and the peaks non-existent Almost at the high values. Was obtaining the results different of shapes and areas, there symmetric, semi-symmetric and asymmetric and asymmetric is majority.

5-at calculate the smaller covered area and the volume of the aerosols particles deposited, notice that the curve is exponential decreasing that was sedimenting particles smallscale take more time to fall, and whenever the time of the deposition increasing then the small particles can be deposited where that small volume of the aerosol particles are depositing at the final hours because number of effects such as the wind speed in night.

\section{REFERENCES}

[1] Bassim M. Hashim*, Dr.Maitham A. Sultan," Using remote sensing data and GIS to evaluate air pollution and their relationship with land cover and land use to Baghdad city" International Applied Geological Congress, Department of Geology, Islamic Azad University - Mashad Branch, Iran, 26-28 April , 2010.

[2] White, H., 1986: On the theoretical and empirical basis for apportion extinction by aerosols: A critical Review. Atmos. Envir., 20, 1659-1672.

[3] Ahmed F. Hussun" Properties of Urban boundary layer and their effects on variation of atmospheric aerosols concentration Particles over Baghdad city" ALMustansiriyah University (2010).

[4] W. Patrick Arnott et al."Towards Aerosol LightAbsorption Measurements with a 7-Wavelength Aethalometer: Evaluation with a Photoacoustic Instrument and 3-Wavelength Nephelometer" (2005).Aerosol Science and Technology, 39:17-29, 2005 Copyright _c American Association for Aerosol Research.

[5] Michael D. King, Yoram J. K, Didier T., and Teruyuki N.," Remote Sensing of Troposphere Aerosols from Space: Past, Present, and Future" American Meteorological Society, Vol. 80, No. 11, November 1999.

[6] C.J. Wong et al."Using Image Processing Technique for the Studies on Temporal Development of Air 
Quality"(2007) School of Physics, UniversitiSains Malaysia, 11800 USM, Penang, Malaysia.

[7] Xiaolei Yu, Zhaocong Wu," Study on the Relationship Between Aerosol Anthropogenic Component and Air Quality in the City of Wuhan" IEEE978-1-42449171,2001

[8] A. Bayat, H. R. Khalesifard, and A. Masoumi," Retrieval of aerosol single scattering albedo and polarized phase function from polarized sun-photometer measurements for Zanjan atmosphere" Atmos. Meas. Tech. Discuss., 6, 3317-3338, 2013.

[9] Internet(http://www.nasa.gov/centers/langley/news/facts heets/Aerosols.html)

[10] Faiza Ali et al."Evaluation and statistical analysis of the measurements of the total outstanding minutes and bullets in the air of the city of Baghdad for the year (2008)"Iraqi Ministry of the Environment (http://www.moen.gov.iq/lastest-stadies.html).

[11] Hon Marian L Hobbs"Good practice guide for monitoring and management of visibility in New Zealand"ISBN 0-478-24035-X, 406, pp.10-11, Ministry for the Environment, August 2001
[12] Internet (http://blog.icoproject.org).

[13] Stern, A.C."Air Pollution"Acadamic press Inc., 1976.

[14] Korhonen, P., M. Kulmala, A. Laksonen, Y. Viisanen, R. Mc. Grew, and J. H. Seinfeld "Ternary nucleation of $\mathrm{H} 2 \mathrm{So} 4, \mathrm{NH} 3$ and $\mathrm{H} 2 \mathrm{O}$ in the atmosphere" J. Geoph. Res., 104, 1999.

[15] Seaton, A., W. Macuee, K., Donaldson, and D. Godden"Particulate air pollution and acute health effects"The Lancent, 345, 176-178, 1995.

[16] Peter K. Kaiser "Comparison of static visual acuity between snellen and early treatment diabetic retina patly study charts", Kalpana, Karlhick J., Jayrajinis. 24 February 2013

[17] Daniel Herrington,"Easy image processing camera interfacing for robotics", www.atmel.com.2003.

[18] R.C.Gonzalez, "Digital image processing”, second edition University of Tennessee, (2001).

[19] Internet (http://ar.wikipedia.org/wiki/Baghdad).

[20] Internet (http://www.meteoseism.gov.iq) 16/3/2013. 